\title{
MONITORING OF RIVER CONTAMINATION DERIVED FROM ACID MINE DRAINAGE USING AIRBORNE IMAGING SPECTROSCOPY (HYMAP DATA, SOUTH-WEST SPAIN)
}

\author{
J. BUZZI ${ }^{\mathrm{a}}$, A. RIAZA*, E. GARCÍA-MELÉNDEZ ${ }^{\mathrm{b}}$, V. CARRÈRE ${ }^{\mathrm{c}}$ AND S. HOLZWARTH ${ }^{\mathrm{d}}$ \\ ${ }^{\text {a }}$ Geological Survey of Spain, IGME, Madrid, Spain \\ ${ }^{\mathrm{b}}$ Facultad de Ciencias Ambientales, Universidad de Leon, Leon, Spain \\ c Laboratoire de Planétologie et Géodynamique de Nantes, CNRS, Nantes, France \\ ${ }^{\mathrm{d}}$ German Remote Sensing Data Center, Imaging Spectroscopy Group, German Aerospace Research Center, Wessling, Germany
}

\begin{abstract}
Imaging spectroscopy is used in this work as an essential mapping tool to monitor changes in contaminated river sediments. Multidate hyperspectral image data (HyMap) are utilized to identify spatial mineral patterns, to detect temporal changes in mineralogy and to link these changes with geochemical processes and short-term climate characteristics.

River sediments contaminated by acid mine drainage are covered by crusts with variably hydrated iron sulphate. The mineralogy of the crusts and the grain size of the underlying fluvial sediments overlap. The spectra used to build up maps from HyMap data are diagnosed mineralogically with archive spectral libraries from pyrite oxidation minerals from well-known sequences of minerals.

The maps compiled from hyperspectral imagery display generalized oxidation shown by the coatings over river sediments following warm and dry periods with low water level. After the wet periods, the area covered by oxidized mineralogical phases recedes in favour of hydrated sulphate.

The iteration of image processing algorithms and the mineralogical and potential contamination in a geological context are described. Change detection of the mineral crusts on the river sediments by mapping using hyperspectral remote sensing data may thus enable a quantitative and qualitative environmental evaluation by the regulators. Copyright (C) 2014 John Wiley \& Sons, Ltd.
\end{abstract}

key wor ds: imaging spectroscopy; hyperspectral remote sensing; river geomorphology; acid mine drainage; climate variability

Received 8 April 2014; Revised 25 June 2014; Accepted 11 September 2014

\section{INTRODUCTION}

The present work focuses on the study of temporal changes of contaminating substances along a river through their spectral responses with hyperspectral airborne HyMap data. The spectral relationships with river micromorphology, river sediment catches and enhanced contamination spots are the targets to define aimed at designing a reliable monitoring system (Coulthard and Macklin, 2003).

Imaging spectroscopy using hyperspectral data with a large number of channels within the visible and nearinfrared wavelength range has been developed as an effective tool to study mine waste deposits generating acid mine drainage (Plumlee, 1999; Swayze et al., 2000). Spectral libraries are gathered for the purpose (Crowley et al., 2003), enabling a quick mineral diagnosis of ephemeral thin crusts concentrating heavy metals, precipitated from acid water using high spectral resolution imagery. Visible-near-infrared spectroscopy has been used to explore the contamination in river sediments and associated

\footnotetext{
*Correspondence to: A. Riaza, Geological Survey of Spain, IGME, Madrid, Spain.

E-mail: a.riaza@igme.es
}

vegetation (Kooistra et al., 2001, 2003, 2004). Imaging spectroscopy is used in this work as an essential mapping tool that summarizes effectively spectral responses from highly spatially heterogeneous mineral crusts covering the river sediments (Riaza et al., 2011b; Buzzi, 2012), as an expression of complex sedimentary and geochemical interacting processes controlled by geomorphology on every scale.

The previously observed mineralogical changes in mine waste associated with the underlying microgeomorphology suggest short-term climate variability following seasonal and annual climate change (Riaza and Müller, 2010; Riaza et al., 2011a). The mineralogical evolution of the SotielAlmagrera mine site over several stages of its recovery process, including dump cleaning and removal of mud tailings, is mapped with the same method (Buzzi, 2012).

The fluvial sediments of the river Odiel have drawn special attention, whilst gathering spills from numerous mine sites in its drainage basin along most of the flow path (Riaza and Carrere, 2010; Riaza et al., 2012; Buzzi, 2012). Further quantitative estimations of spectral features were tested focusing on absorption depth, full width at half maximum and asymmetry using spectral derivatives and modified Gaussian models (Buzzi et al., 2011). 


\section{SITE DESCRIPTION}

The river Odiel (Huelva, south-west Spain) runs through the Iberian Pyrite Belt, a wide geological unit within the Hesperian Massif hosting massive sulphide deposits exploited over 5000 years (Figure 1). Pyrite is abundant both on mine waste and rock outcrops, and acid mine drainage is present in most drainages throughout the region (Sarmiento et al., 2009). River sediments are used in nearby drainage basins as contamination indicators (Gonçalves et al., 1992; Soares et al., 1999). Preliminary analysis and mineralogy of precipitates and efflorescent sulphate salt from various locations on the Pyrite Belt have been open to the public (Sanchez España et al., 2005).

The mine site of Sotiel is located in the middle course of the river. The mine works are displayed along the river, with large dumps, tailings and ponds. The river was used as a washing system, numerous walls being built along the area where mine dumps occur. As a consequence, the river flow is artificially slowed and water is pooled.

Climate is the most important factor influencing the geochemical pattern of the secondary minerals precipitating on the river flow path. The yearly precipitation regime in Huelva consists of intense and short rain events in autumn, relatively dry winters and a dry spring and summer. The river carries acid waters with products from solutions of iron sulphide during flash floods. After the annual main flash flood in October, sediments lose water and oxidize continuously during the winter, spring and summer (Sarmiento et al., 2009), following a well-known mineral sequence (Buurman, 1975).

Over the span of the years 2005-2009 of the available HyMap flights, the climate has changed remarkably.

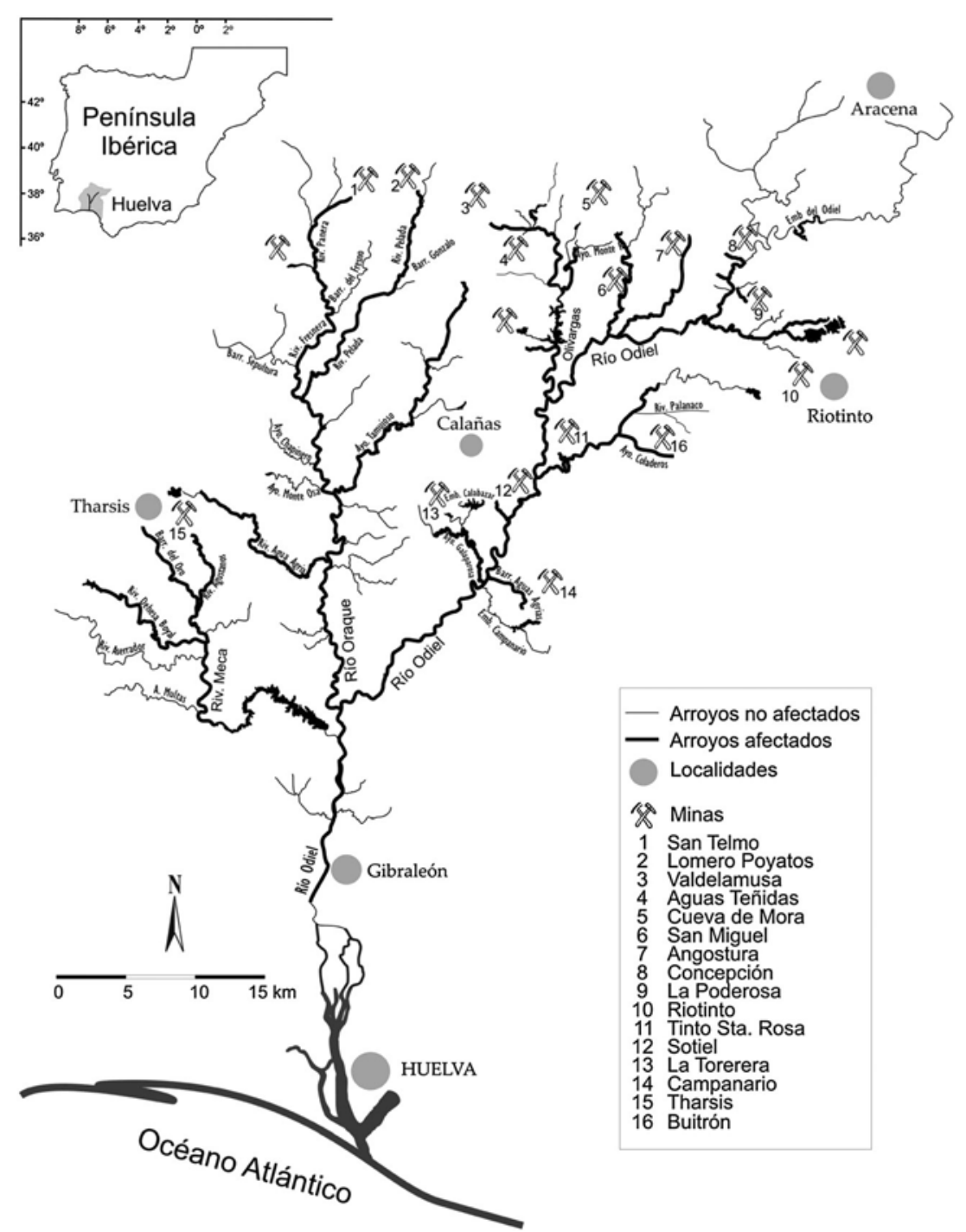

Figure 1. River basin of the river Odiel, with contaminated parts enhanced (in Sarmiento et al., 2009) 
According to the yearly climate estimations, 2005 was a very warm and very dry year (Weather Agency of Spain, AEMET, http://www.aemet.es). The year 2008 was a warm year in temperature and neutral in terms of rain rate, recovering very warm temperatures in 2009 and a neutral rain rate. In summary, the annual temperature increased from 2008 to 2009, but the rainfall rate was similar.

The amount of river flow is directly related to the rainfall rate. After the usual yearly flood in October, washing away all efflorescences and crusts on the river flow path, a slow process of decreasing water flow begins. Wide areas of river sediments emerge during the summer depending on temperature and available humidity in the atmosphere (Figure 2).

Most of those minerals are unstable and are dissolved or transported in intense rain events. If oxidation is intense, they can be transformed to stable phases as goethite or hematite, acting like a permanent cement of fluvial sediments and sealing the bottom of the river flow path to water infiltration.
The spectral behaviour of the sediments on the river should respond through the mineralogy of crusts and efflorescences formed by precipitation of acid mine waters to such climate changes. Therefore, major attention has been focused on the spectral features that reveal the changes in the oxidation and hydration degree of the coatings over river sediments. Discovering how this process is experienced on the river and which parameters are critical in its development is the aim of this work.

\section{DATA SET}

Imagery

HyMap data were acquired over the Odiel River path on 17 July 2005, 4 August 2008 and 13 August 2009. HyMap is an airborne hyperspectral sensor with 126 wavebands from 436 to $2485 \mathrm{~nm}$ with a spectral resolution of $10-20 \mathrm{~nm}$. Its spatial resolution is $5 \mathrm{~m}$.
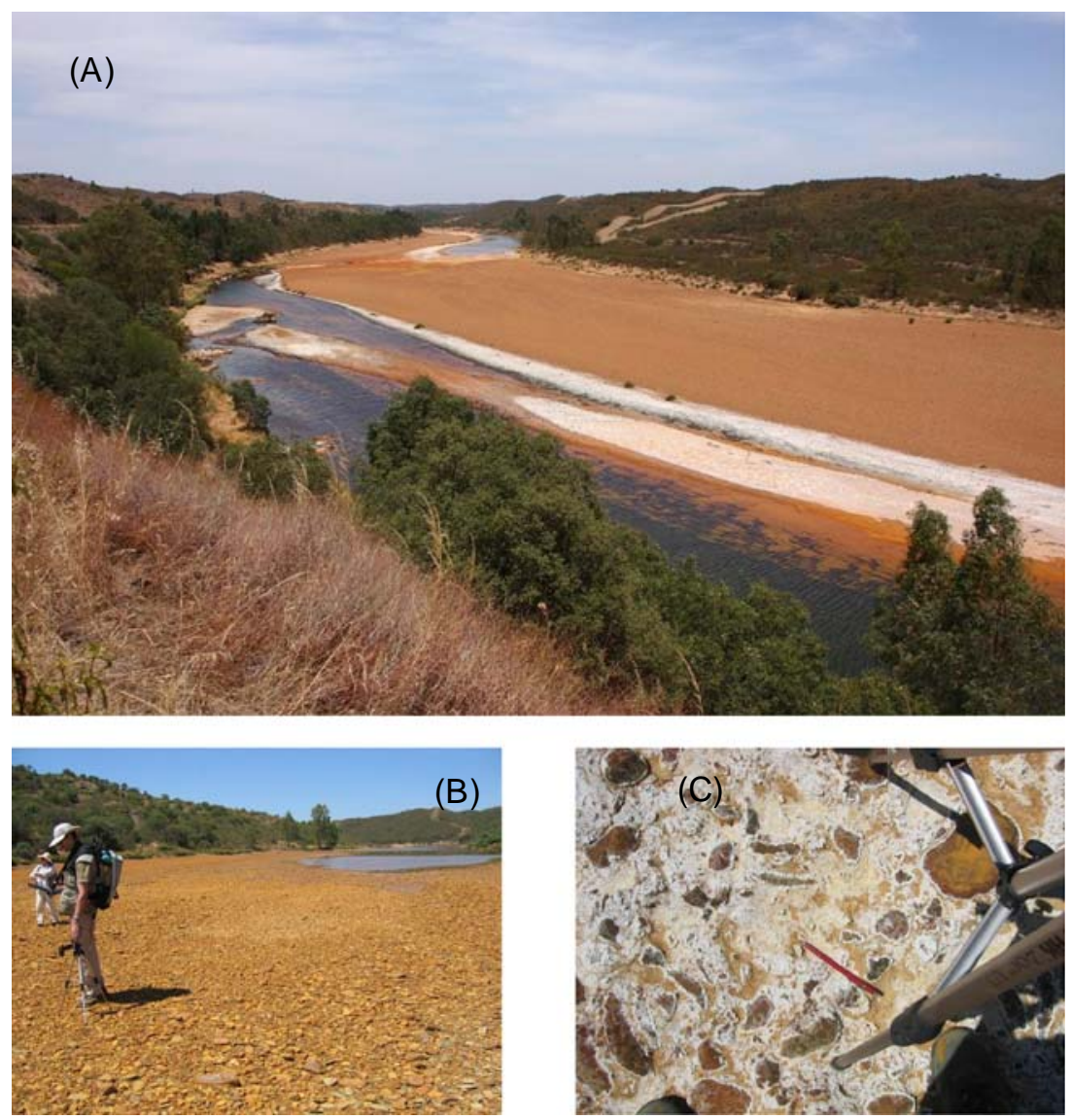

Figure 2. (A) Panoramic view of the river Odiel, with well-developed river bars, at low flow stage. Whitish ribbons near the water are crusts of hydrated iron sulphate, overlaying fine-grained sands. Dominant reddish colours are coatings of iron oxides and hydroxides covering boulders and coarse-grained sands and gravels. Intense orange colours, whether over the water or immersed, are typical pyrite mud. (B) Operator measuring field spectra with an ASD FieldSpec portable spectrometer over oxidized boulders. (C) Crusts of hydrated iron sulphate covering the top of a river bar with boulders of heterogeneous sizes. This figure is available in colour online at wileyonlinelibrary.com/journal/rra 
The raw HyMap data are first system corrected by HyVista (Cocks et al., 1998). The raw digital numbers are corrected for dark current and converted to physical units of at-sensor radiance (unit: $\mathrm{uW} / \mathrm{cm}^{2} \mathrm{sr}^{1} \mathrm{~nm}{ }^{1}$ ) using laboratory radiometric calibration and in-flight measurements of on-board calibration sources.

The imagery was geocoded at the German Space Agency (DLR) using software on the basis of a parametric approach determining the viewing geometry for each pixel on the basis of sensor-specific parameters, flight parameters such as sensor position and attitude (i.e. roll, pitch and true heading) and additional terrain information from a digital terrain model (digital elevation model), resulting in a typical accuracy of about 2 pixels (Richter and Schläpfer, 2002).

For atmospheric correction, ATCOR4 was used (Richter and Schläpfer, 2002). This physically based approach, using the MODTRAN radiative transfer code, corrects for atmospheric effects, as well as adjacency scattering, and BRDF compensation in order to derive nadir-normalized ground reflectance. Furthermore, topographic correction for different terrain illumination is applied. With ground measurements for a reference target taken during the overflight, an additional vicarious calibration is carried out. On the basis of field spectroscopic measurements of large and spectrally homogeneous targets, the image reflectance values are validated against the field measurements and-if necessary-adjusted.

\section{Field and laboratory spectra}

Field measurements were taken with an ASD FieldSpec 3 Spectrometer (ASD Inc., Boulder, CO, USA) during the 2005, 2008 and 2009 campaigns for sensor calibration and thematic purposes. This device measures ground reflectance spectra covering the wavelength range from 350 to $2500 \mathrm{~nm}$.

Ground spectral measurements were taken during flights as reference targets to allow an additional vicarious calibration. Image reflectance values can be validated comparing them with field spectroscopic measurements over large and spectrally homogeneous areas. Around 100 spectral measurements were taken per calibration target, using bare fibre, which gives a field of view of about $60 \mathrm{~cm}$ diameter at a height of $1 \mathrm{~m}$ above ground.

Additionally, field spectra were collected for geological interpretation. Fieldwork was conducted in the summers of 2005, 2006, 2007, 2008, 2009 and 2010. Around 1700 geologically documented spectra were measured both in the field and in the laboratory from field samples collected between 2005 and 2010. The imagery along the entire flow path of the Odiel River was analysed with an ASD FieldSpec 3 Spectrometer (Figure 2) for thematic purposes (Riaza and Carrere, 2010; Buzzi et al., 2012).

Details on the procedure to take spectral measurements both in the field and laboratory are described in previous work (Riaza and Müller, 2010; Riaza et al., 2011a). Eighteen existing spectra from sulphide oxidation products in public domain spectral libraries (Clark et al., 2007; Crowley et al., 2003) were used as references with the Spectral Analyst (RSI, 2000) to obtain a comparative score of similarity for spectra selected as end members to build maps from HyMap images. The whole spectral wavelength range is taken into account for mineralogical diagnosis, rather than single absorption features. In this way, hyperspectral imagery provides a superior performance in the geological interpretation of spectral features compared with multispectral image data.

\section{Additional data}

The basic relationships between field and imagery spectra and their mineralogical diagnosis are established in previous work on mine sites (Riaza et al., 2006; Riaza and Müller, 2010). The spectral pattern displayed by river sediments on HyMap imagery on the river Odiel follows the geomorphological trends observed on mine dumps and nearby river sediments. Selected representative samples were analysed by X-ray diffraction to confirm the mineralogical spectral diagnosis. Selected samples of river sediments were also collected for conventional mineralogical analysis.

\section{IMAGE PROCESSING AS A GEOLOGICAL MAPPING TOOL}

Imaging spectroscopy provides wide possibilities for mapping complex surface features over the earth. Hyperspectral images provide high dimensional data with a good signalto-noise ratio and good spatial resolution (Hubbard and Crowley, 2005). The procedure of feature extraction for thematic purposes was performed following an interpreteroriented sequential spectral unmixing routine with standard algorithms. This is a sequence aimed at noise reduction and reduction of data dimensionality and extraction of geological information, ending on a geological map of the river sediments (Figure 3).

The standard sequence of algorithms is minimum noise fraction transforms (MNFTs), pixel purity index and n-dimensional analysis to extract significant statistical populations (RSI, 2000). The reality of a particular land cover is determined by the spectral response of the regions of interest that correspond to the resulting populations. A land use map was computed with Spectral Angle Mapper (Kruse et al., 1993) using the appropriate end members.

A second MNFT was computed on the geometrically and atmospherically corrected HyMap image that isolated relatively open land devoid of vegetation. The flow path was precisely drawn, with some areas strongly disturbed by forests or quarries. For those areas, a mask was built, and the 


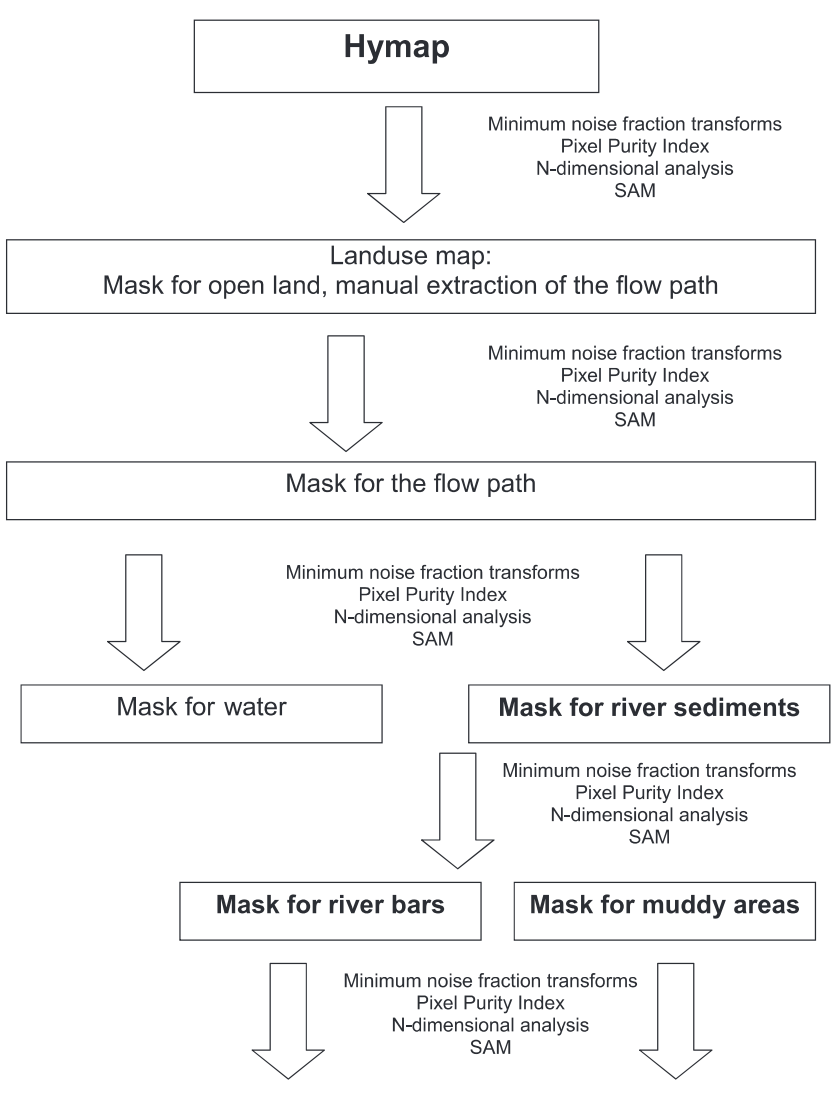

\section{MAP OF COATINGS OVER RIVER SEDIMENTS}

Figure 3. Sequence of algorithms used to produce a map from HyMap data

flow path was manually extracted as a mask to be used during further processing (Figure 4B). MNFTs were again computed on the HyMap imagery for the area masked for the flow path. The resulting pattern displayed the sinuous shapes typically associated with river geomorphology.

Identification of correct water types is critical to the mapping process. The spectral signature of acidic water can be misidentified as a number of hydrated pyrite weathering products. Moreover, margins of pebble river bars are often fine-grained sands covered with wet pyrite mud, narrow belts of efflorescent salts or drying vegetation, all of which have significant spectral features that can be misinterpreted if not carefully evaluated. Some plants, which may root on the muddy or sandy bottom of a river, are considered typical of acidic waters (e.g. Klebsormidium sp.) and can influence the spectral mixture of water, particularly when water levels are low and transmissivity of the water is high. The muddy or sandy bottom can also contribute to the spectral response of shallow acidic water if there is no vegetation.

The seventh MNFT computed from the whole HyMap image identifies efficiently water; a mask was then built from those data (Figure 4C). The flow path mask and the water mask were combined into a single mask used to map emerged (uninundated) river sediments (Figure 4F). MNFTs were again computed under this flow path, excluding water. After the pixel purity index procedure and n-dimensional analysis, the populations that are going to be the end members for input to the Spectral Angle Mapper were identified, and the final map of the river flow path was constructed. Using the same procedure for subscenes within a scene yields somewhat different results. A general map was built for the flight line (Figure 4G).

As referred to previously in the text, 18 existing spectra from sulphide oxidation products in public domain spectral libraries (Clark et al., 2007; Crowley et al., 2003) were used as references with the Spectral Analyst (RSI, 2000) to obtain a comparative score of similarity for spectra selected as end members to build maps from HyMap images.

Spectral Angle Mapper, Spectral Feature Fitting and binary encoding were taken into account in equal weighting in the final similarity score with a maximum of 1 . The Spectral Angle Mapper determines the spectral similarity between two spectra by calculating the angle between spectra, treating them as vectors in a space with dimensions equal to the number of bands (Kruse et al., 1993). Spectral Feature Fitting compares the fit of image spectra with selected reference spectra using a least-squares technique (Clark et al., 1990). The binary encoding algorithm encodes the data and end member spectra into zeros and ones, on the basis of whether a band falls below or above the spectrum mean (Goetz et al., 1985).

The scores per sample from the Spectral Analyst for the three algorithms are displayed in a table for each map considered. The minerals are displayed in the table using a sequence of oxidation and dehydration, to ease identification of trends (Table 1). The three minerals with the best scores per sample are displayed in the table and labelled in spectral library graphs. General trends and small changes in mineralogical identification can thereby be traced in detail. The mineralogical diagnosis extracted from the Spectral Analyst per geological unit digitally mapped from HyMap images is shown as a colour coding on the map described by the legend.

The legend of the maps of coatings over river sediments precipitated from acid mine drainage includes all minerals of the reference spectral library on minerals associated with iron sulphide mine waste products (Crowley et al., 2003). Colour coding for minerals mapped with the corresponding chemical formula is arranged in a precipitation and oxidation sequence. Increasing reddish colours suggest intense oxidation. Bluish and greenish colours concentrate on hydrated areas. Only part of the mineralogical sequence shows up in the map. The colour pattern of the map displays at first sight the pyrite oxidation intensity on the coatings to the 

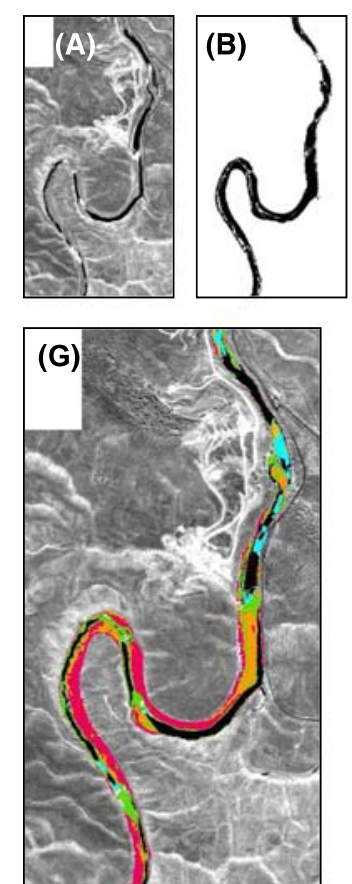
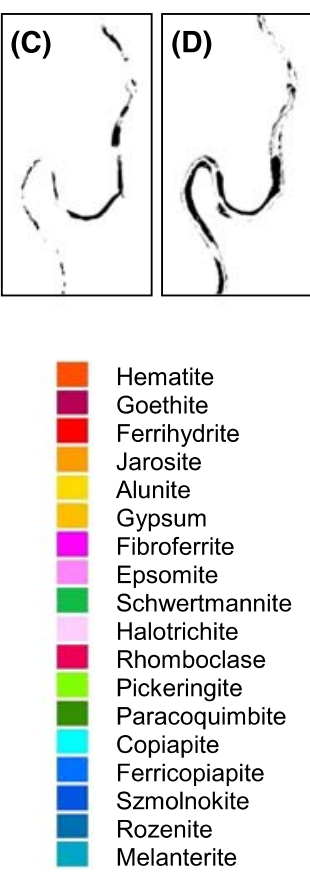
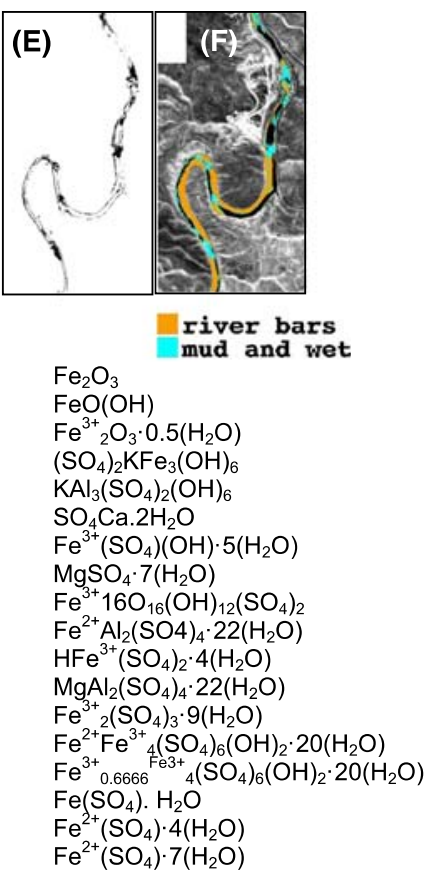

Figure 4. Sequential subscenes produced by image processing (from left to right). (A) HyMap channel 28 (0.846 $\mu \mathrm{m})$ showing the flow path and water. (B) Mask for the flow path. (C) Mask for water. (D) Mask for river bars. (E) Mask for muddy areas. (F) Map of river bars and muddy areas. (G) Map of crusts of AMD minerals over river sediments (in Buzzi, 2012). Legend including all minerals of the reference spectral library on minerals associated with iron sulphide mine waste products (Crowley et al., 2003) in a progressive sequence. This figure is available in colour online at wileyonlinelibrary.com/journal/rra

reader. It permits an immediate change detection evaluation when watching several maps of the same area from different dates and shows the geochemical evolution to a learned interpreter at first sight.

A geographic information system change detection procedure would enhance changes in resulting maps, if in a continuous monitoring system. However, the available surfaces mapped are too small to provide publishable evidence.

\section{VALIDATION: CHALLENGES ON THE GEOLOGICAL INTERPRETATION OF REFLECTANCE IN A CONTAMINATED RIVER USING HYPERSPECTRAL AIRBORNE DATA}

The resulting map is an image of the variable reflectance of the scene and was constructed by interpreters who are knowledgeable of the geological context of the contamination products. However, designing a legend that accurately describes the mapped geological units involves complex quantitative evaluation (Riaza et al., 2011a), summarized in the preceding section. Conventional geological mapping skills and geological interpretation of aerial photography are required to validate maps produced through image processing.

The river carries acid waters with products from solution of iron sulphide during annual flash floods in October. Crust of precipitates cover the river sediments that oxidize continuously during the winter, spring and summer. The coatings present over sediments during the summer HyMap flight disappear rapidly and are no longer present when the maps are compiled.

HyMap imagery does display a progressive evolution of mineral growth on geomorphologically identifiable surfaces along the river path. Coatings of precipitate from acid water over river sediments are subject to grain-size and slope effects. Goethite coatings cover the coarser pebbles on top of the river bars. Jarosite tends to develop over the pebbles and sands of the sides river bars (Figures 4 and 7). Schwertmannite grows on ribbons along the steeper sides of the river bars over fine-grained sands close to water. Melanterite, a highly hydrated iron sulphate, may appear on isolated pools over silt and mud, preferably on severe drought times, when flow rate lessens.

Validation by single-point ground truth of single geological parameters and misclassification estimations (Carbonneau and Bergeron, 2005; Dugdale et al., 2010) is impossible in this complex geological context. The evaluation and validation of maps was performed through detailed and systematic fieldwork gathering geological and spectral observations on the relationships between the different mineral coatings and their location over river sediments, closely associated with the grain-size pattern of the sediments of the 
Table I. Scores obtained by Spectral Analyst in HyMap spectra

\begin{tabular}{|c|c|c|c|c|c|c|c|c|c|c|c|c|c|c|c|c|c|c|}
\hline \multicolumn{19}{|c|}{ Mineral products of pyrite oxidation } \\
\hline Spectra ID & 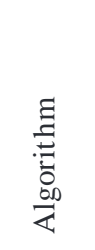 & 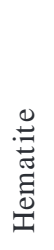 & 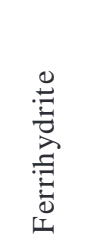 & $\begin{array}{l}\stackrel{\Xi}{\Xi} \\
\text { பี } \\
0 \\
0\end{array}$ & 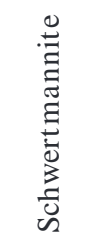 & 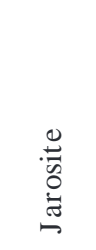 & 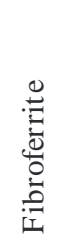 & $\stackrel{\stackrel{\Xi}{\Xi}}{\stackrel{\Xi}{\Xi}}$ & 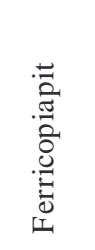 & 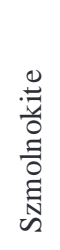 & 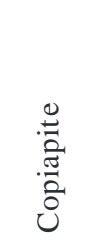 & 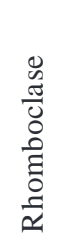 & 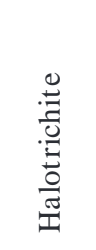 & 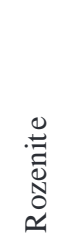 & 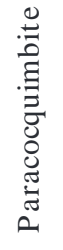 & 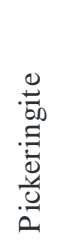 & 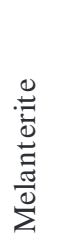 & 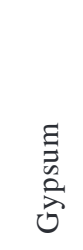 \\
\hline \multirow[t]{4}{*}{ soilveg } & SAM & & 0.853 & 0.870 & 0.899 & & & & & & & & & & & & & \\
\hline & SFF & & 0.560 & 0.574 & 0.611 & & & & & & & & & & & & & \\
\hline & $\mathrm{BE}$ & & 0.864 & 0.904 & 0.904 & & & & & & & & & & & & & \\
\hline & Total & & 2.277 & 2.384 & 2.414 & & & & & & & & & & & & & \\
\hline \multirow[t]{4}{*}{ sandbar1 } & SAM & & 0.887 & 0.906 & 0.893 & & & & & & & & & & & & & \\
\hline & SFF & & 0.436 & 0.509 & 0.527 & & & & & & & & & & & & & \\
\hline & $\mathrm{BE}$ & & 0.952 & 0.992 & 0.944 & & & & & & & & & & & & & \\
\hline & Total & & 2.275 & 2.407 & 2.363 & & & & & & & & & & & & & \\
\hline \multirow[t]{4}{*}{ sandbar2 } & SAM & & & 0.906 & 0.902 & 0.868 & & & & & & & & & & & & \\
\hline & SFF & & & 0.669 & 0.701 & 0.565 & & & & & & & & & & & & \\
\hline & $\mathrm{BE}$ & & & 0.976 & 0.944 & 0.896 & & & & & & & & & & & & \\
\hline & Total & & & 2.551 & 2.548 & 2.330 & & & & & & & & & & & & \\
\hline \multirow{4}{*}{ sandbar3 } & SAM & & & 0.883 & 0.907 & 0.861 & & & & & & & & & & & & \\
\hline & SFF & & & 0.589 & 0.639 & 0.505 & & & & & & & & & & & & \\
\hline & $\mathrm{BE}$ & & & 0.888 & 0.920 & 0.872 & & & & & & & & & & & & \\
\hline & Total & & & 2.360 & 2.466 & 2.238 & & & & & & & & & & & & \\
\hline \multirow[t]{4}{*}{ sandbar4 } & SAM & & & 0.844 & 0.863 & 0.892 & & & & & & & & & & & & \\
\hline & SFF & & & 0.409 & 0.443 & 0.401 & & & & & & & & & & & & \\
\hline & $\mathrm{BE}$ & & & 0.864 & 0.928 & 0.848 & & & & & & & & & & & & \\
\hline & Total & & & 2.117 & 2.234 & 2.140 & & & & & & & & & & & & \\
\hline \multirow[t]{4}{*}{ hydrate crust } & SAM & & & & & & & 0.761 & & & 0.688 & & 0.596 & & & & & \\
\hline & SFF & & & & & & & 0.183 & & & 0.532 & & 0.448 & & & & & \\
\hline & $\mathrm{BE}$ & & & & & & & 0.800 & & & 0.600 & & 0.680 & & & & & \\
\hline & Total & & & & & & & 1.743 & & & 1.820 & & 1.724 & & & & & \\
\hline \multirow[t]{4}{*}{ mud } & SAM & & & & & & & 0.746 & & & 0.750 & & & & & & & 0.637 \\
\hline & SFF & & & & & & & 0.000 & & & 0.000 & & & & & & & 0.000 \\
\hline & BE & & & & & & & 0.896 & & & 0.792 & & & & & & & 0.856 \\
\hline & Total & & & & & & & 1.642 & & & 1.542 & & & & & & & 1.493 \\
\hline \multirow[t]{4}{*}{ mud2 } & SAM & & & & & & & 0.727 & 0.637 & & 0.741 & & & & & & & \\
\hline & SFF & & & & & & & 0.000 & 0.145 & & 0.234 & & & & & & & \\
\hline & $\mathrm{BE}$ & & & & & & & 0.832 & 0.640 & & 0.664 & & & & & & & \\
\hline & Total & & & & & & & 1.559 & 1.422 & & 1.638 & & & & & & & \\
\hline
\end{tabular}

SAM, Spectral Angle Mapper; SFF, Spectral Feature Fitting; BE, binary encoding.

The minerals from the spectral library are displayed in the first line (Crowley et al., 2003). The lines correspond to spectra in the second column.

The scores for SAM, SFF and BE and their totals are displayed in four lines per spectra below the corresponding minerals identified per spectra. The higher score per spectra is emphasized with bold numbers. The three identified minerals per spectra are labelled on spectral graphs as first, second and third choices according to the score. Note that the position of the scores in the table indicates the oxidation state of the sample. Scores shifting to the left indicate intense oxidation, whereas scores shifting to the right indicate a comparatively hydrated state.

river bars. Single-point field spectral measurements with a portable spectrometer help to understand the spectral response of HyMap imagery, mixing mineralogically heterogeneous surfaces, which have already disappeared on the ground when the map is compiled. The maps provided in this study must be understood as simplified images of mineralogical trends in a highly spatially heterogeneous environment on all scales, which rapidly changes over time, not only yearly or seasonally but also weekly.
The challenges associated with mineralogical interpretation of such maps using available data and algorithms, and the difficulty of extracting useful geological information for temporal contamination monitoring from hyperspectral data, and field and laboratory spectra, are previously discussed in depth (Riaza et al., 2011b). Spectral behaviour trends extracted from the images, and in the laboratory from geological evaluations, provide reliable indicators for monitoring contamination from mine wastes in river sediments. 


\section{J. BUZZI ET AL.}
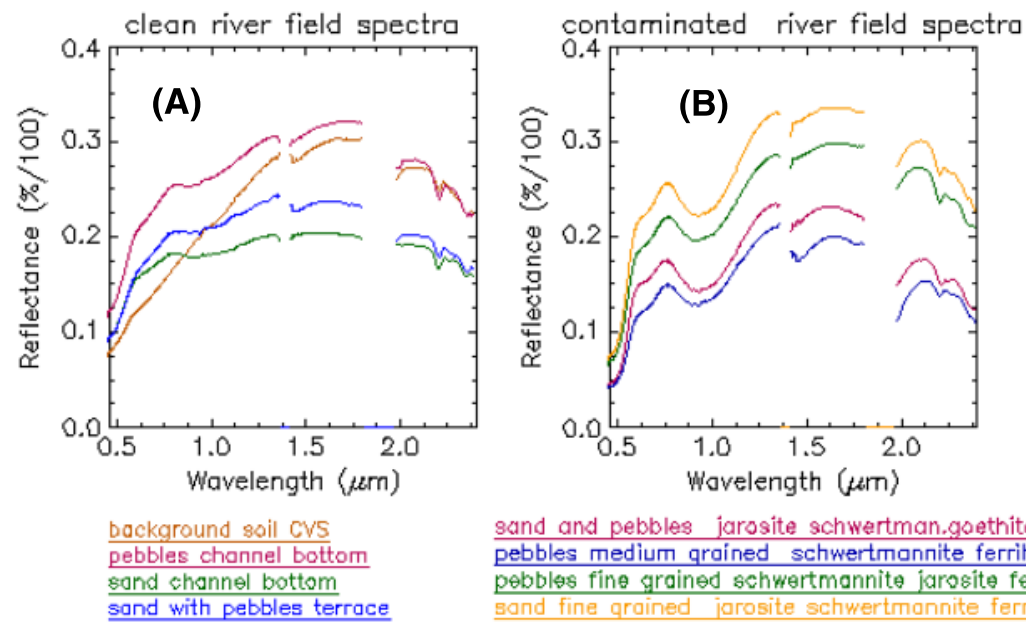

sand and pebbles jarosite schwertman.goethite pebbles medium qrained schwertmannite ferrihydrite qoethite pebbles fine grained schwertmannite jaresite ferrihydrite sand fine qrained jarosite schwertmannite ferrihydrite

Figure 5. Field spectra on detritic sediments on the bottom of the river channel. (A) Tributary to the river Odiel clean from contamination by acid mine drainage precipitates. (B) Bottom of the channel detrital materials from the contaminated river Odiel. Mineralogical diagnose of coatings using a laboratory spectral reference library (Crowley et al., 2003). This figure is available in colour online at wileyonlinelibrary. com/journal/rra

\section{RESULTS}

Spectral behaviour of coatings over river sediments: main trends

The first map produced from HyMap imagery, regardless of the widespread cover of contaminated crusts, is a map of river sediments (Riaza et al., 2012). The HyMap images have a spectral response directly related to the grain size of the sediments in the riverbed. The spectra used as end members to map the river sediments are mineralogically diagnosed with the US Geological Survey reference spectral library for pyrite weathering products (Crowley et al., 2003; Riaza and Müller, 2010), and the mineralogical diagnosis builds up a new legend.

Most of the river flow path is contaminated by acid mine drainage precipitates (Figures 1 and 2). The spectral response of the detrital materials of clean tributaries and contaminated paths is quite diverse (Figure 5). The field spectra of the soil in the volcano-sedimentary complex, the geological unit hosting most ore deposits in the Pyrite Belt (Figure 5A), shows a straight ascending line in the visible wavelength range. Pebbles and sand on the bottom of the channel show smoothed absorption features related to iron and enhanced narrow absorptions at $2.2 \mu \mathrm{m}$ and weak $2.3 \mu \mathrm{m}$ typical of muscovite (Riaza and Carrere, 2010). Comparatively, the spectra on the contaminated river Odiel show enhanced absorptions typical of iron-bearing oxihydroxides and sulphate and lacking enhanced muscovite features (Figure 5B). Such enhanced features permit the spectral isolation of contaminated areas on the flow path, the elaboration of masks to perform detailed image processing and the availability of suitable subscenes to qualify the mapping of contamination products.
The iron-bearing sulphate crusts dominate the coarsegrained river sediments on top of bars, such as boulders and sands. The coatings are mineralogically diagnosed as goethite or jarosite (Figure 6).

The ribbons of coatings closer to the edge of water, covering fine-grained sands, or mud, are typically diagnosed as schwertmannite or more hydrated iron sulphate as copiapite (Figure 6). The most common spectral feature is the presence of an absorption at $670 \mathrm{~nm}$ because of the presence of weeds and aquatic vegetation (Riaza et al., 2012). This feature is present with variable overall reflectance in wet areas and areas close to the edge of water that have been recently submerged.

The spectral feature of water is diagnosed as hydrated sulphate as copiapite, if the areas with a water surface are not

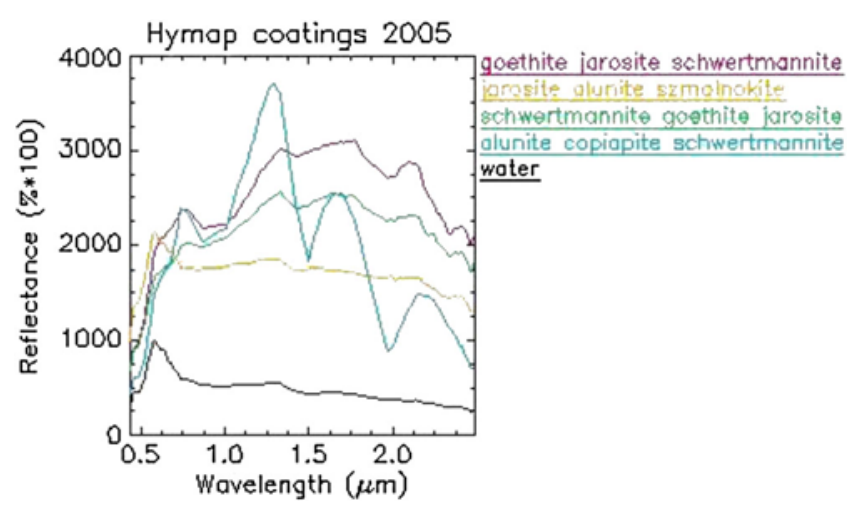

Figure 6. Spectra from HyMap flight of 2005 from the end members used to build the geological map on Figure 3 with the mineralogical diagnosis using the pyrite weathering minerals library as reference (Crowley et al., 2003) for the spectra on the graph. This figure is available in colour online at wileyonlinelibrary.com/journal/rra 

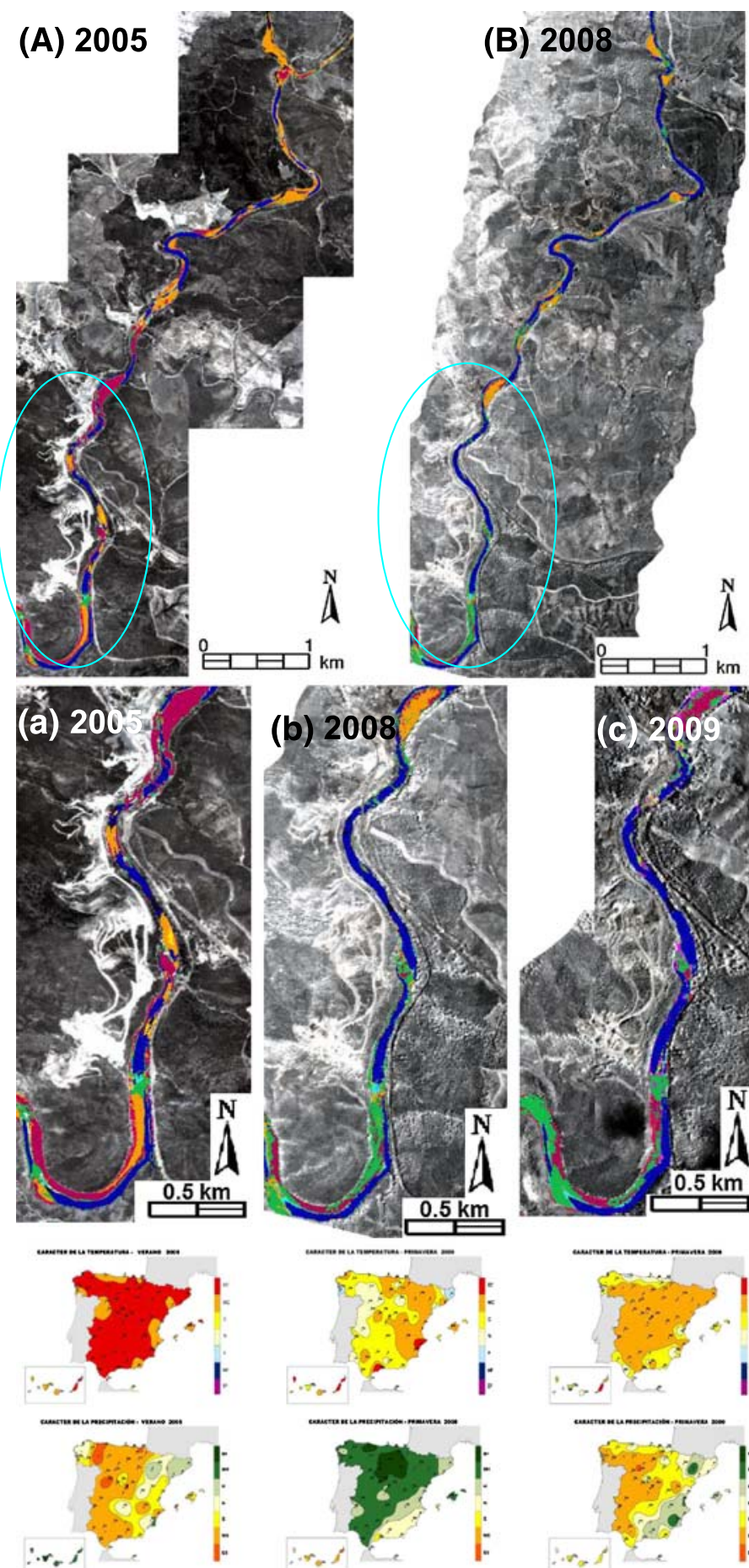

2005
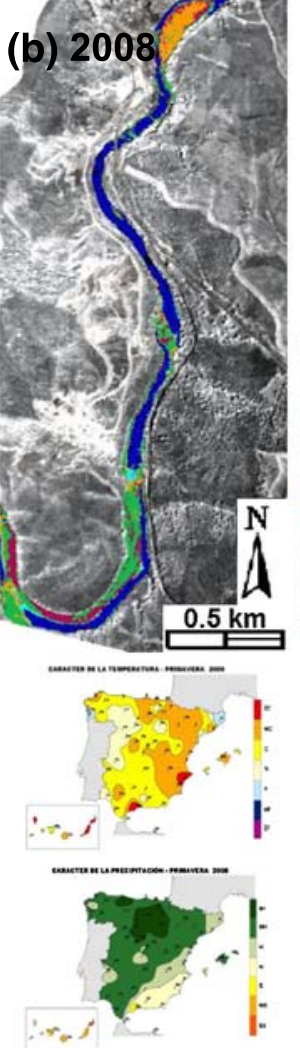

2008
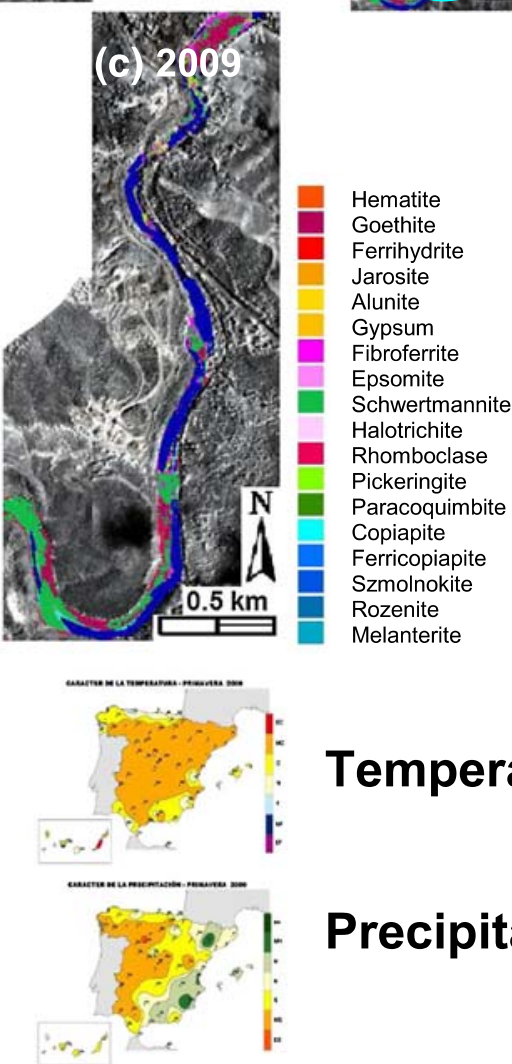

2009

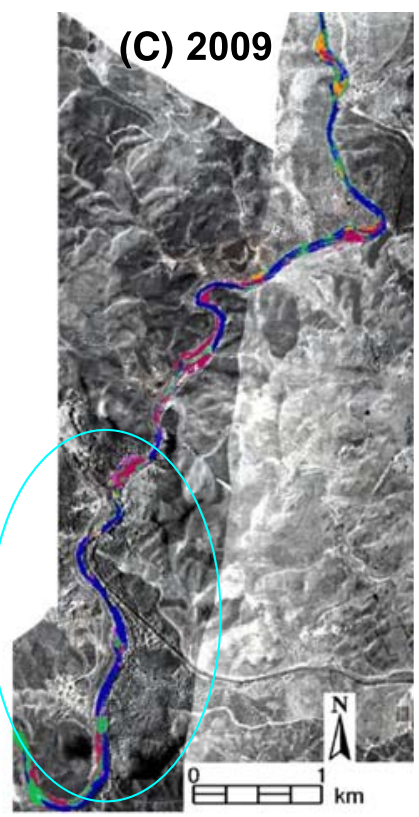

$\mathrm{Fe}_{2} \mathrm{O}_{3}$

$\mathrm{FeO}(\mathrm{OH})$

$\mathrm{Fe}^{3+} \mathrm{O}_{3} \cdot 0.5\left(\mathrm{H}_{2} \mathrm{O}\right)$

$\left(\mathrm{SO}_{4}\right)_{2} \mathrm{KFe}_{3}(\mathrm{OH})_{6}$

$\mathrm{KAl}_{3}\left(\mathrm{SO}_{4}\right)_{2}(\mathrm{OH})_{6}$

$\mathrm{SO}_{4} \mathrm{Ca} .2 \mathrm{H}_{2} \mathrm{O}$

$\mathrm{Fe}^{3+}\left(\mathrm{SO}_{4}\right)(\mathrm{OH}) \cdot 5\left(\mathrm{H}_{2} \mathrm{O}\right)$

$\mathrm{MgSO}_{4} \cdot 7\left(\mathrm{H}_{2} \mathrm{O}\right)$

$\mathrm{MgSO}_{4} \cdot 7\left(\mathrm{H}_{2} \mathrm{O}\right)$

$\mathrm{Fe}^{2+} \mathrm{Al}_{2}(\mathrm{SO} 4)_{4} \cdot 22\left(\mathrm{H}_{2} \mathrm{O}\right)$

$\mathrm{HFe}^{3+}\left(\mathrm{SO}_{4}\right)_{2} \cdot 4\left(\mathrm{H}_{2} \mathrm{O}\right)$

$\mathrm{MgAl}_{2}\left(\mathrm{SO}_{4}\right)_{4} \cdot 22\left(\mathrm{H}_{2} \mathrm{O}\right)$

$\mathrm{Fe}^{3+}{ }_{2}\left(\mathrm{SO}_{4}\right)_{3} \cdot 9\left(\mathrm{H}_{2} \mathrm{O}\right)$

$\mathrm{Fe}^{2+} \mathrm{Fe}^{3+}{ }_{4}\left(\mathrm{SO}_{4}\right)_{6}(\mathrm{OH})_{2} \cdot 20\left(\mathrm{H}_{2} \mathrm{O}\right)$

$\mathrm{Fe}^{3+}{ }_{0.6666}{ }^{\mathrm{Fe} 3+}{ }_{4}\left(\mathrm{SO}_{4}\right)_{6}(\mathrm{OH})_{2} \cdot 2 \mathrm{O}\left(\mathrm{H}_{2} \mathrm{O}\right)$

$\mathrm{Fe}\left(\mathrm{SO}_{4}\right) \cdot \mathrm{H}_{2} \mathrm{O}$

$\mathrm{Fe}^{2+}\left(\mathrm{SO}_{4}\right) \cdot 4\left(\mathrm{H}_{2} \mathrm{O}\right)$

$\mathrm{Fe}^{2+}\left(\mathrm{SO}_{4}\right) \cdot 7\left(\mathrm{H}_{2} \mathrm{O}\right)$

Figure 7. The mine site works in the middle course. Maps of coatings over river sediments diagnosed with the reference spectral library (Crowley et al., 2003). (A) Map of coatings over river sediments compiled from HyMap data in 2005. (B) Map of coatings over river sediments compiled from HyMap data in 2008. (C) Map of coatings over river sediments compiled from HyMap data in 2009. (a, b and c) Detail of meander of maps displayed in (A), (B) and (C). Legend including all minerals of the reference spectral library on minerals associated with iron sulphide mine waste products (Crowley et al., 2003) in a progressive sequence. Below: temperature and precipitation seasonal summer maps for the corresponding year of flights above (AEMET, Weather Agency of Spain). Reddish colour for temperature indicates extreme warm, and orange-yellow indicates moderately warm. Green colour for precipitation indicates very wet, and orange or yellow indicates moderate summer rainfall rate (in Buzzi, 2012). This figure is available in colour online at wileyonlinelibrary.com/journal/rra 
properly masked in the HyMap imagery before the mineralogical diagnosis. Figure 5 shows similar absorption features between the spectra of water and coatings mineralogically diagnosed as jarosite, alunite and szmolnokite, with only higher overall reflectance. Such misdiagnoses are frequent, and the compilation of the final map requires a careful interpretation (Riaza et al., 2012) in the geological context.

\section{Temporal changes along the river Odiel}

The precipitates from acid mine drainage by dissolution of pyrite weathering products covering the fluvial sediments along the river Odiel through time change under the influence of climate and environmental water availability (Buzzi, 2012; Buzzi et al., 2012).

As expected, according to rainfall rates in spring and average rainfall and temperature in the seasons previous to the flight, the level of the water in 2005 was lower than in 2008 and 2009 (Figure 7c). In spite of the comparatively heavy rains in spring 2008, the water was levelled in 2008 and 2009 at this point. The numerous walls crossing the river slow down water flow and reduce differences caused by climate changes. Only extremely poor rainfall and high temperatures in 2005 showed an obvious decrease in water flow in this section.

The main trend in the diagnosed mineralogy is a generalized oxidation of the precipitated sulphate after dry and warm periods with a low water level, as observed in the summer of 2005. The coarser sediments on top of the river bars are covered by highly oxidized minerals, such as goethite, whereas finer sediments are mainly covered by less oxidized minerals, such as jarosite. More hydrated minerals, such as schwertmannite, are located next to the water, where there is a regular supply of humidity.

The most hydrated phases present, such as copiapite, are developed on wet and muddy surfaces that have been recently flooded. After wet periods, such as winter and spring 2008, with intense rainfalls, the area covered by oxidized mineralogical phases covering the river sediments recedes in favour of hydrated sulphate. Thus, in the summer of 2008, there was a lower degree of oxidation in the river sediments, with a wider presence of schwertmannite all along the river Odiel, whereas goethite and other oxidized minerals remained on top of the river bars as smaller surfaces than in 2005. The summer of 2009 was preceded by a decrease in the water level. Many areas previously flooded became emerged and were covered by comparatively more hydrated sulphate, such as schwertmannite and copiapite. Alternating ribbons diagnosed with different mineral phases trace the recent history of flooding in the area.

The neighbourhood of sources of contamination can be traced locally by the mineralogy of the coatings on the river sediments. Their mineralogical changes interact with water level and climate parameters on differing identifiable paths of mineralogical changes on coatings over river sediments shown by HyMap imagery.

\section{DISCUSSION}

The mineral diagnosis using reference spectral libraries for pyrite weathering products produces consistent maps of mineral crusts over river sediments from HyMap data, on the basis of sedimentary and geochemical processes controlled by geomorphology, which follow simple relationships previously established in mine waste.

Mapping the contamination over the river with hyperspectral airborne data is possible using overlapping flight lines without major disturbance between spectral variations from adjacent flight lines.

There is a clear spectral response distinguishing areas with contaminated substances from areas free from contamination carried by run-off, both on HyMap imagery and field spectra.

Progressive subscening isolating masks in areas of potential mineralogical spectral targets is necessary. Nevertheless, the size of many of the mapped geological units, consistent with field observations, is smaller than the spatial resolution of the imagery. HyMap data are proved to be a formidable mapping tool of contaminating substances on river sediments.

The atmospheric correction of the imagery is crucial for producing representative maps on substances precipitated from acid mine drainage. Discriminating from more oxidized and intensely hydrated substances is ensured. But minor distinction between mineralogical phases, which are closed in the sequence of dehydration on HyMap imagery, can be jeopardized by the atmospheric correction.

Both grain size on river sediments and precipitated substances are related to the neighbourhood of water. Both spectral responses get mixed when mapping mineralogical phases precipitated from acid mine drainage over river sediments.

When using spectral libraries as references on a sequence of mapping algorithms, it is important to rely on the end members produced from the statistical process previous to the map resulting from the Spectral Angle Mapper. The spectra from regions of interest representing the geological units in the final map are smoothed and less representative of the spectral features diagnosing the geological units mapped.

\section{CONCLUSIONS}

The mineralogical changes on the precipitates over the sediments of the river Odiel with hyperspectral HyMap imagery are mapped through three nonconsecutive years. Such changes respond to climate parameters, water dynamics and distance to the sources of contamination in a complex 
pattern. Imaging spectroscopy has proved to be an efficient tool for studying temporal changes in a rapidly changing geological environment.

Mapping contamination products from sulphide mine waste on a river flow path involves a previous careful mapping of the river sediments and minor topographical features changing the water dynamics. The minor topography provides the favourable locations to monitor contaminant mineral development.

Changes in the water level of the river under variable climate, and the pattern of river sediments, explain the geochemical evolution of the precipitates from acid mine drainage from dissolved pyrite weathering products.

A sequence of mapping algorithms is established to produce a final map summarizing the main geological units relevant to the spectral response to contamination on a river course.

The influence on the spectral response of sedimentological parameters on the river sediments, such as grain size, and climate-dependent water level is discussed on the maps. Both field spectra and HyMap-derived spectra have contributed to the interpretation.

The final maps are an accurate geomorphological record of the river sediments and their overlaying coatings of contaminating substances. They tell faithfully the geomorphological and geochemical history of the river from the source to the mouth.

The resulting maps and the geomorphological-related and climate-related relationships drawn are a solid basis for a routine quantitative and qualitative monitoring of acid mine drainage contamination on the river Odiel using hyperspectral HyMap data.

\section{ACKNOWLEDGEMENTS}

This research was funded by the National Research Plan of Spain (PNI, project numbers CGL2005-02462, CGL200601544/CLI and CGL2007-60004/CLI) and the Research Staff Training Programme (BES-2008-003648). The University of Nantes (France) provided training on advanced spectral analytical techniques (PNI, Short Stage SEST1000I001495XVO). J. M. Moreira contributed with information about mine inventories and regional environmental databases. The Andalusian Regional Government, the Junta de Andalucía, permitted entry to the abandoned mine site of Sotiel at the border of the river. Local industries also allowed access to the river through their facilities.

\section{REFERENCES}

ASD. 2006. FieldSpecR 3 user manual, ASD document 600540 Rev. F 2006. Analytical Spectral Devices, Inc. http://www.asdi.com
Buurman P. 1975. In vitro weathering products of pyrite. Geologie Mijnvouw 54: 101-105.

Buzzi J 2012. Imaging spectroscopy to monitor the contamination from sulphide mine waste in the Iberian Pyrite Belt using hyperspectral sensors (Huelva, Spain). PhD Universidad de León, 14th December 2012.

Buzzi J, Carrère V, Riaza A, García-Meléndez E, Bachmann M. 2011.Modified Gaussian modelization applied to hyperspectral data in an AMD-contaminated area. Case of Odiel river (Huelva, SW Spain), 2011, In: Proceedings 7th EARSeL Workshop on Imaging Spectroscopy, Edinburgh, Scotland, 11th-13th April 2011. http://www.earsel2011.com/ Proceedings/

Buzzi J, Riaza A, Garcia-Melendez E, Holzwarth S. 2012. Change detection in sediments of a river affected by acid mine drainage using airborne hyperspectral HyMap data (river Odiel, SW Spain). Proceedings 4th Workshop on 'Remote Sensing and Geology'. 24th-25th May 2012, Mykonos (Greece): 134-158.

Carbonneau PE, Bergeron N. 2005. Automated grain size measurements for airborne remote sensing for long profile measurements of fluvial grain sizes. Water Resources Research 41: W11426, DOI: 10.1029/2005WR003994.

Clark RN, Gallagher AJ, Swayze GA. 1990. Material absorption band depth mapping of imaging spectrometer data using the complete band shape least-squares algorithm simultaneously fit to multiple spectral features from multiple materials. In: Proceedings of the Third Airborne Visible/Infrared Imaging Spectrometer (AVIRIS) Workshop 1990; JPL Publication 90-54: 176 - 186.

Clark RN, Swayze GE, Wise R, Livo E, Hoefen T, Kokaly R, Sutley SJ. 2007. USGS digital spectral library. Digital Data Series 231. http:// speclab.cr.usgs.gov/spectral- lib.html.

Cocks T, Jenssen R, Stewart A, Wilson I, Shields T 1998. The HyMapTM airborne hyperspectral sensor: the system, calibration and performance. In: Proceedings 1st EARSEL Workshop on Imaging Spectroscopy, Zürich, October 1998.

Coulthard TJ, Macklin MG. 2003. Modeling long-term contamination in river systems from historical metal mining. Geology 31-5: 451-454. http://geology.gsapubs.org/content/31/5/451.abstract.

Crowley JK, Williams DE, Hammarstrom JM, Piatak N, Chou I-M, Mars JC. 2003. Spectral reflectance properties $(0.4-2.5 \mathrm{~m})$ of secondary Feoxide, Fe-hydroxide, and Fe-sulphate-hydrate minerals associated with sulphide-bearing mine wastes. Geochemistry:Exploration,Environment, Analysis3-3:219-228(10). http://geea.lyellcollection.org.

Dugdale SJ, Carbonneau PE, Campbell D 2010. Aerial photosieving of exposed gravel bars for the rapid calibration of airborne grain size maps. Earth Surface Processes and Landforms 35: 627-639. DOI: 10.1002/ esp.1936.

Goetz AFH, Vane G, Solomon JE, Rock BN. 1985. Imaging spectrometry for earth remote sensing. Science 228: 1147-1153. DOI: 10.1126/ science.228.4704.1147

Gonçalves EPR, Boaventura RAR, Mouvet C. 1992. Sediments and aquatic mosses as pollution indicators for heavy metals in the Ave River basin (Portugal). Science of the Total Environment 114: 7-24. http://dx.doi. org/10.1016/0048-9697(92)90410-T

Hubbard BE, Crowley JK, 2005. Mineral mapping on the Chilean-Bolivian Altiplano using co-orbital ALI, ASTER and Hyperion imagery, data dimensionality issues and solutions. Remote Sensing of Environment 99: 173-186. http://dx.doi.org/10.1016/j.rse.2005.04.027

Kooistra L, Wehrens R, Leuven RSEW, Buydens LMC. 2001. Possibilities of visible-near-infrared spectroscopy for the assessment of soil contamination in river floodplains. Analytica Chimica Acta 446,1-2: 97-105. http://dx.doi.org/10.1016/S0003- 2670(01)01265-X

Kooistra L, Wanders J, Epema GF, Leuven RSEW, Wehrens R, Buydens LMC. 2003. The potential of field spectroscopy for the assessment of sediment properties in river floodplains. Analytica Chimica Acta 484: 289-200. http://dx.doi.org/10.1016/S0003- 2670(03)00331-3 
Kooistra L, Salas EAL, Clevers JGPW, Wehrens R, Leuven RSEW, Nienhuis PH, Buydens LMC. 2004. Exploring field vegetation reflectance as an indicator of soil contamination in river floodplains. Environmental Pollution 127-2: 281-290. http://dx.doi.org/10.1016/S0269-7491(03)00266-5

Kruse FA, Lebkoff AB, Boardman JB, Heidebrecht KB Shapiro, AT Barloon, PJ Goetz AFH. 1993. The spectral imaging processing system (SIPS) - interactive visualization and analysis of imaging spectrometer data. Remote Sensing of Environment 44: 145-163. 10.1016/0034-4257 (93)90013-N

Plumlee GS. 1999. The environmental geology of mineral deposits. Part A: processes, techniques, and health issues. Reviews in Economic Geology 6A: 71-116.

Riaza A, Carrere V. 2010. Monitoring of superficial contamination produced by massive sulphide mine waste along the Odiel River (Andalousia, Spain) using hyperspectral data. In: IGARSS 2009, 13th-17th July 2009, Cape Town (South Africa). Geoscience and Remote Sensing Symposium, 2009, IEEE International, IGARSS 20093 III: 1701-1704. DOI: 10.1109/ IGARSS.2009.5417966.

Riaza A, Müller A. 2010. Hyperspectral remote sensing monitoring of pyrite mine wastes: a record of climate variability (Pyrite Belt, Spain). Environmental Earth Sciences 61-3: 575. DOI: 10.1007/s12665-009-0368-y.

Riaza A, Ong C, Müller A. 2006. Dehydration and oxidation of pyrite mud and potential acid mine drainage using hyperspectral dais 7915 data (Aznalcóllar, Spain), In ISPRS Mid-Term Symposium 2006 'Remote Sensing: From Pixels To Processes', Enschede, The Netherlands, 8-11 May 2006, The International Archives of the Photogrammetry, Remote Sensing and Spatial Information Sciences 2006 34- XXX: 1. http:// www.isprs.org/proceedings/XXXVI/part7/PDF/175.pdf

Riaza A, Garcia-Melendez E, Müller A. 2011a. Spectral identification of pyrite mud weathering products: a field and laboratory evaluation. International Journal of Remote Sensing 32-1: 185-208. DOI: 10.1080/ 01431160903439957.
Riaza A, Buzzi J, García-Meléndez E, Carrère V, Müller A. 2011b. Monitoring the extent of contamination from acid mine drainage in the Iberian Pyrite Belt (SW Spain) using hyperspectral imagery. Remote Sensing 3: 2166-2186; DOI: 10.3390/rs3102166.

Riaza A, Buzzi J, García-Meléndez E, Carrère V, Sarmiento A, Müller A. 2012. River acid mine drainage sink by coastal tides: sediment and water mapping through hyperspectral HyMap data. International Journal of Remote Sensing 33-19: 6163-6185. DOI: 0.1080/01431161.2012.675454.

Richter R, Schläpfer D. 2002. Geo-atmospheric processing of airborne imaging spectrometry data. Part 2: atmospheric/topographic correction. International Journal of Remote Sensing 23: 2631-2649. DOI: 10.1080/ 01431160110115825. RSI 2000, ENVI User's Guide. Research Systems Inc. Publications. http://www.exelisvis.com/portals/0/pdfs/enviex/ENVI_ EX_User_Guide.pdf

RSI. 2000. ENVI User's Guide. Research Systems Inc. Publications.

Sanchez España J, Lopez Pamo E, Santofimia E, Aduvire O, Reyes J, Barettino D. 2005. Acid mine drainage in the Iberian Pyrite Belt (Odiel river watershed, Huelva, SW Spain): geochemistry, mineralogy and environmental implications. Applied Geochemistry 20: 1320-1356. http://dx. doi.org/10.1016/j.apgeochem.2005.01.011

Sarmiento AM, Nieto JM, Olías M, Cánovas CR. 2009. Hydrochemical characteristics and seasonal influence on the pollution by acid mine drainage in the Odiel River basin (SW Spain). Applied Geochemistry 24: 697-714. http://dx.doi.org/10.1016/j.apgeochem.2008.12.025

Soares HMVM, Boaventura RAR, Machado AASC, Esteves da Silva JCG. 1999. Sediments as monitors of heavy metal contamination in the Ave River basin (Portugal): multivariate analysis of data. Environmental Pollution 105-3: 311-323. http://dx.doi.org/10.1016/S0269-7491(99)00048-2.

Swayze GA, Smith KS, Clark RN, Sutley SJ, Pearson RM, Vance JS, Hageman PhL, Briggs PH, Meier AL, Singleton MJ, Roth S. 2000. Using imaging spectroscopy to map acidic mine waste. Environmental Science and Technology 34: 47-54. DOI: 10.1021/es990046w. 